\title{
Naturalistic Intelligence
}

\section{Matthew N. O. Sadiku1, Tolulope J. Ashaolu ${ }^{*}$, and Sarhan M. Musa1}

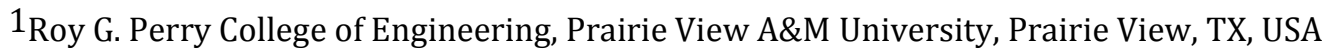 \\ 2 College of Food Science, Southwest University, Tiansheng Road Beibei District, Chongqing, 400715, P.R. China \\ E-mail: sadiku@ieee.org; ashaolut@gmail.com; smmusa@pvamu.edu \\ *corresponding author details: Dr. Tolulope J. Ashaolu, ashaolut@gmail.com
}

\begin{abstract}
Naturalistic intelligence is one of the multiple intelligences proposed by researcher Howard Gardner. Naturalistic intelligence refers to a person's interest in the "natural" world of animals, plants, and the natural work around them. It is the ability to identify and classify patterns in natural environment. Individuals with naturalist intelligence have a sensitivity to and appreciation for nature. Naturalists are inspired and rejuvenated by nature. This paper provides an introduction on naturalistic intelligence.
\end{abstract}

Keywords: intelligence; naturalistic intelligenc; , multiple intelligence

\section{INTRODUCTION}

Intelligence or cognitive development is a bio-psychological potential to process information that can be activated to solve problems. It is the ability to learn from experience and to adapt to, shape, and select environments. It has traditionally been thought of as an inherited entity that one is born with and cannot be changed.

Professor Gardner at Harvard's Graduate School of Education argued that there are better or alternative ways to measure intelligence than standard IQ tests. He first proposed nine intelligences and insists that all people are born with one or more intelligences and that people can be smart in a number of different ways. This implies that we are all intelligent in different ways. Naturalist intelligence is one of Howard Gardner's nine multiple intelligences, which involves how sensitive a person is to nature and the world.

\section{WHAT IS NATURALISTIC INTELLIGENCE?}

In 1983, Howard Gardner published seven types of intelligence in his famous book [1]. These are: verbal/linguistic, mathematical/logical, spatial, musical, kinesthetic, interpersonal, and intrapersonal. Figure 1 illustrates Howard Gardner's theory of multiple intelligences [2]. In 2006 (twenty-three years later), Gardner added an eighth branch to his model in his another book [3]. This eighth branch is known as naturalistic intelligence. Naturalistic intelligence is a new addition that meets Gardner's criteria an intelligence. According to Gardner, naturalistic intelligence is the ability to identify, classify, and manipulate elements of the environment, objects, animals or plants. The intelligence has to do with being in tune with nature and one's natural environment. It can be seen in weather forecasting, gardening, cooking, civil engineering, landscape design, and /plant/animal classifications. Like other intelligences or strengths, naturalistic intelligence is not fixed like a standard IQ. It can grow and develop throughout a person's life. Figure 2 illustrates naturalistic intelligence[4]. A naturalistic person or naturalist is someone who possesses high naturalistic intelligence. Naturalists learn best when the subject is related to something prominent in nature. They have the sense to appreciate life and its wonders. They are "nature-smart." They show interest in natural elements, like gardens, forests, mountains, etc. They have an affinity for animals, plants, vegetables, and fruit. They have an uncanny ability to make observations and distinctions about nature. People with high naturalistic intelligence often find their way into careers that focus on environmental science, botany, biology, ecology, astronomy, zoology, agriculture, horticulture, archaeology, volcanology, oceanography, geology, meteorology, or forensic science. Historical figures with the highest naturalistic intelligence include Charles Darwin, George Washington Carver, Rachel Carson, Alexander von Humboldt, Jacques Cousteau, Carl Sagan, and Al Gore. Figure 3 shows a typical naturalist [5].

Naturalistic intelligence should not be confused with natural intelligence, which offers insight about how to equip machines with human-like capabilities. Natural intelligence uses AI in building devices that get the job done. Also, naturalistic intelligence is not worshipping nature, as some suggest. There is a significant relationship between naturalist intelligence and environmental attitude. Some regard naturalistic intelligence as environmental awareness.

\section{CHARACTERISTICS OF NATURALIST INTELLIGENCE}

Individuals with high naturalistic intelligence show an inclination towards the natural world. They have the following unique characteristics [6, 7]:

- They express a desire to understand how things work.

- They care about the environment and like to be in touch with nature.

- They like to explore and discover new species and behaviors.

- They are interested in using tools to help observation microscopes, binoculars, and telescopes.

- They specialize or take courses related to nature (such as botany, ecology, zoology, etc.)

- They specialize as gardeners, farmers, scientists, ecologists or veterinarian 
- They are sensitive to and appreciative of nature

- They enjoy gardening and feel alive when in contact with nature

- They have a hobby that involves nature

- They are environmentally conscious and are bothered by pollution

- They participate in environmental or nature preservation causes

- They care for animals and/or plants and enjoy having pets

- They read nature books or magazines

- They may be interested in joining the Boy or Girl Scouts

Besides these general characteristics, the characteristics related to naturalistic intelligence can also be divided in left and right brain strengths. Left being the more analytic. Characteristics related to the right side of the brain are [8]:

- Feels at their best in the outdoors

- Strives for balance with nature and mind and body

- Demonstrates an empathy with nature and it is creatures

- Has a strong sense of responsibility towards the environment

- Possesses a sensitivity to animal abuse and environmental destruction

- $\quad$ Enjoys exploration, adventure, open-ended experiences

- Feels an affinity toward animals in general, pets in particular

Characteristics related to the left side of the brain are [8]:

- Analyses of information

- Has an eye for detail

- Sees patterns

- Identifies categories

- Reasons in hierarchy (can rank items by significance and relationship)

- Memorizes schematically

- Looks for structure

- Understands statistics

- Prefers charts, timelines

- Has a strong interest in ecology, biology, or chemistry

\section{MEASUREMENT OF NATURALISTIC INTELLIGENCE}

Armstrong has used the following ten statements to measure naturalistic intelligence in his "Multiple Intelligences Profile Assessment" [9]:

1. I write well and enjoy putting thoughts on paper (or in the computer).

2. I enjoy telling stories or jokes.

3. I enjoy word games like Scrabble or Anagrams.

4. I enjoy reading books and magazines.

5. I have a good vocabulary.

6. I enjoy communicating by talking or writing.

7. Malay/English and histories were among my favorite subjects in school.

8. When I walk down the pathway in town, I pay more attention to the words on billboards than to the people around.

9. I enjoy entertaining others or myself with tongue twisters, nonsense rhymes, limericks, or puns.

10. I get more out of listening to the radio or a spokenword cassette than I do from television or films

\section{DEVELOPING NATURALIST INTELLIGENCE}

As children grow, it is necessary to ensure that the naturalistic intelligence contributes to their attitudes and behaviors towards the environment. Children who are "nature smarts" may enjoy TV shows, games, and stories that deal with nature, animals or natural phenomena. They enjoy being outside playing, looking, seeking, gardening, camping, hiking, climbing, exploring, and getting their hands dirty. Children with high naturalistic intelligence tend ask endless questions about what they observe.

Naturalist intelligence can be developed in childhood or later in life. It can be developed by using appropriate teaching methods. Activities that a teacher might use to reach students should focus on direct observation and exploration of the natural world. Help them think through how what they are learning impacts the world. Since naturalistic intelligence is much a hands-on experience, the best way to develop naturalistic intelligence is by getting outside. Go outside, appreciate nature, and admire the trees, the grass, the flowers, etc. You may take a field trip. For example, if a person moves from an urban area to a rural area, he might become exposed to fields, hiking, and mountains and develop his natural intelligence. The following tips may also help in developing naturalistic intelligence [10]:

- Go on a nature walk

- Cultivate a garden

- Be involved in hands-on activities

- Read books and articles about nature and the environment

- Visit various natural locations and places where they can mingle with nature (including farms)

- Keep a Nature Journal and create observation notebooks

- Describe changes in the local or global environment that affect you

- Become involved in the care for pets, wildlife, gardens, or parks

- Use scientific gadgets such as binoculars, telescopes, microscopes, or magnifiers to see things differently

- Draw or photograph natural objects

- Collect natural organisms - feathers, leaves, flowers etc.

- Celebrate Earth Day on April 22nd.

- Write articles about nature (poems, stories, articles, blogs, etc.)

You can use these tips to help your child or student excel in school. As a result of participating in the activities suggested above,

The following skills will be developed $[11,12]$ :

1. Observation Skills: This is probably the most fundamental skill of naturalist intelligence. Interacting with the nature helps develop observation skills.

2. Empathy: Getting involved in activities that lead to interaction with the environment will help in developing empathy toward people, animals, and nature.

3. Sensitivity: Environmental sensitivity helps to develop concern for the environment and helps the students understand concepts like sustainability and efficiency.

4. Curiosity: Naturalists are known to always ask questions and are curious or inquisitive about the environment. Curiosity is the first step in making new discoveries outside.

5. Motor Skills: Engaging the naturalists in activities that involve collecting, sorting, and discovering will help in developing motor skills and will keep the mind active.

\section{QUOTES ABOUT NATURAL INTELLIGENCE}

The following quotes related to naturalistic intelligence will help your critical thinking [13-15]:

"Intelligence without ambition is a bird without wings -

Salvador Dali.

"Nature is not a place to visit. It is home."-Gary Snyder 
"The garden suggests there might be a place where we can meet nature halfway."-Michael Pollan

The earth has music for those who listen."-George Santayana

"Adopt the pace of nature: Her secret is patience."-Ralph Waldo Emerson

"The human race is challenged more than ever before to demonstrate our mastery, not over nature but of ourselves."-Rachel Carson

"I want my children to understand the world, but not just because the world is fascinating and the human mind is curious. I want them to understand it so that they will be positioned to make it a better place" - Howard Gardner "Both science and history are moving targets. Scholars in the twenty-first century are much more aware than those of earlier generations that scientists operate under the influence of powerful metaphors (science as exploration, discovery, documentation, thrust and counterthrust), and that both the scope and the tools of history undergo continual changes." - Howard Gardner

"There is no such thing as free, nothing is free, so please don't steal, especially from the future" - Environmental Sayings.

\section{BENEFITS AND CHALLENGES}

Naturalistic intelligence is the intelligence deals with the natural, the environment of residence, or anything related to nature. Speculation has it that naturalistic intelligence helped our ancient hunter-gatherer ancestors to identify which flora and fauna were edible and which ones were not. People who have naturalistic intelligence are the ones who wonder about the things they see around them and ask endless questions about what they observe. They make astute observations about natural changes, emerging patterns, and natural phenomena. They love books, shows, or videos about nature or natural phenomena, or animals. They often find their way into professions that deal with or are focused on biology, agriculture, horticulture, and archaeology [16].

Children displaying "nature smarts" are often interested in human behaviors, or the behaviors, habits, or habitats of other species. They may enjoy subjects, shows, and stories that deal with animals or natural phenomena. They show unusual interest in subjects like biology, zoology, botany, geology, meteorology, paleontology, or astronomy [16].

Why is it that the notion of intelligence is too often associated with its opposite, stupidity? White supremacists (some of whom are doctors, educationists, and scientists) have historically labeled minority groups "stupid." Measuring skulls in Nazi Germany "proved" Jews' inferiority. Psychometricians often deny that the subjectivity of the researcher, the prejudices of the researcher, are built into the test. Testing is not innocent. Some find the notion of multiple intelligences superficial, reductionistic, and naïve [17].

\section{CONCLUSION}

Naturalistic intelligence is the ability to understand the natural environment well and enjoy nature, and use that ability productively. It is being in tune with nature and one's natural surroundings. It enables human beings to recognize, categorize, and draw upon certain features of the environment. It is related to how we connect and adjust to our natural surroundings. People with high naturalistic intelligence usually feel most at home when they are outdoors in nature. This is the best way for naturalistic learners to absorb information.

Schools should be teaching to all eight (or nine) intelligences. More information about naturalistic intelligence can be found in the books in $[3,18]$ and in the journal devoted to it: Intelligence.

\section{REFERENCES}

[1] H. E. Gardner, Frames of mind: The Theory of Multiple Intelligence. New York: Basic Book, 1983.

[2] "Naturalistic intelligence," https://app.emaze.com/@ATWFOWLF\#1

[3] H. E. Gardner, Multiple Intelligences: New Horizons in Theory and Practice. Basic Books, 2006.

[4] "Multiple intelligence 8. Naturalistic intelligence," February2016http://brainberg.blogspot.com/2016/ 02/multiple-intelligence-8-naturalistic.html

[5] https://www.youtube.com/watch?v=Jr6_0XVvSW8

[6] "Naturalistic intelligence, the ability to understand environment,"https://www.iberdrola.com/talent/ naturalistic-intelligence

[7] “Naturalishintelligence,"https://www.russellrowe. com/multiple-intelligences/naturalist.pdf

[8] "Naturalistic intelligence," https://www.international-montessori.org/wpcontent/uploads/2014/03/NaturalisticIntelligence.pdf

[9] N. S. Mumthas and T. K. U. Farooque, "Measuring naturalistic intelligence - A contextual and visual approach," July 2012, https://www.academia.edu/9795294/Measuring Naturalistic_Intelligence_A_Contextual_and_Visual_ Approach_Paper_Submitted_for_National_Seminar_ On_Naturalistic_intelligence

[10] "Naturalist intelligence learning from Inspiring Breakthrough," http://www.inspirinbreakthrough.co.uk/learningstyles/naturalist-learning.htm

[11] "Naturalist intelligence," https://greycaps.com/theteacher/Community/Nat uralist-Intelligence

[12] "9 Essential skills of naturalist intelligence (and how they help you),"https://naturementor.com/naturalist-intelligence-skills/

[13] T. O. Kowald, "Educational outdoor activities to build nature smarts," April 2014,

https://www.connectionsacademy.com/support/r esources/article/educational-outdoor-activities-tobuild-nature-smarts

[14] "Quotes about natural intelligence," https://www.quotemaster.org/natural+intelligence

[15] "Howard Gardner quotes," https://www.goodreads.com/author/quotes/3738 1.Howard_Gardner

[16] L. O. Wilson, "The eighth intelligence - Naturalistic intelligence,"

https://thesecondprinciple.com/optimallearning/naturalistic-

intelligence/\#: :text=General\%20Description\%3A $\% 20$ Naturalist $\% 20$ intelligence $\% 20$ deals,or $\% 20$ ha bitats\%20of\%20other\%20species.

[17] M. Morris, "Chapter 8: The eighth one: Naturalistic intelligence," Counterpoints, vol. 278, 2004, pp. 159-173

[18] H. E. Gardner, Intelligence Reframed: Multiple Intelligences for The 21st Century. New York: Basic Books,1999. 


\section{AUTHORS}

Matthew N.O. Sadiku is a professor emeritus in the Department of Electrical and Computer Engineering at Prairie View A\&M University, Prairie View, Texas. He is the author of several books and papers. His areas of research interests include computational electromagnetics and computer networks. He is a fellow of IEEE.

Tolulope J. Ashaolu works at Southwest University. He is the author of several papers and a book. His research interests include functional foods and food microbiology.

Sarhan M. Musa is a professor in the Department of Electrical and Computer Engineering at Prairie View A\&M University, Prairie View, Texas. He has been the director of Prairie View Networking Academy, Texas, since 2004. He is an LTD Sprint and Boeing Welliver Fellow. His areas of research interests include computational electromagnetics and computer networks.

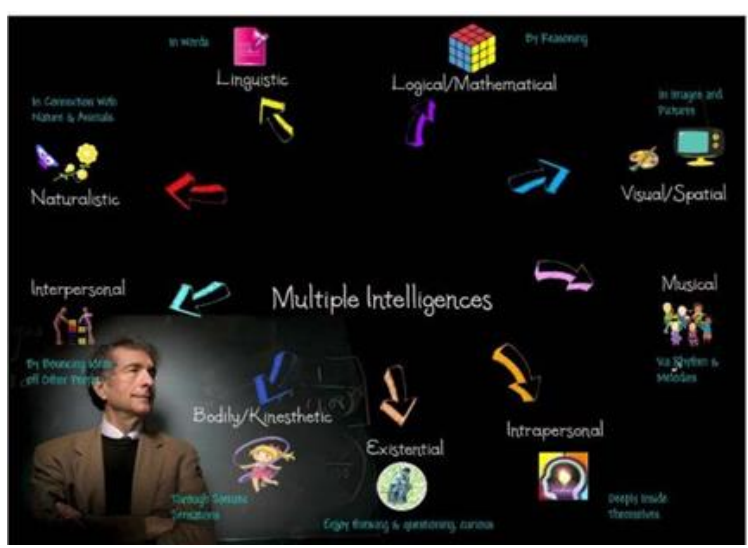

FIGURE 1: HOWARDGARDNER'S THEORY OF MULTIPLE INTELLIGENCES [2].

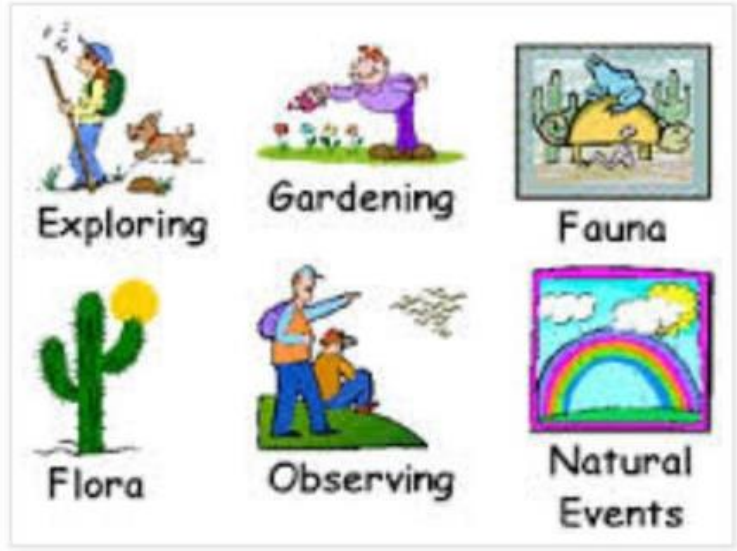

FIGURE 2: AN ILLUSTRATION OF NATURALISTIC INTELLIGENCE [4].

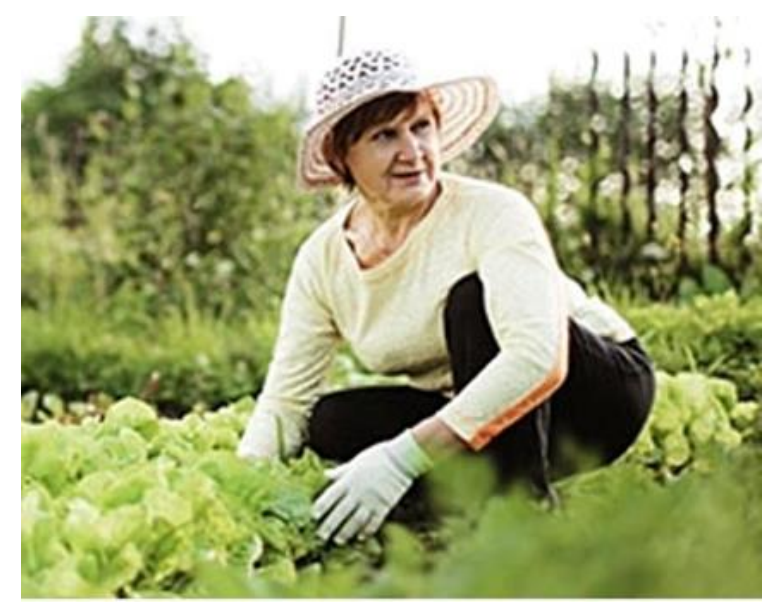

FIGURE 3: A NATURALIST [5] 